\title{
Study of Ultraviolet Emission Spectra in ZnO Thin Films
}

\author{
Y. M. Lu, ${ }^{1}$ X. P. Li, ${ }^{1}$ P. J. Cao, ${ }^{1}$ S. C. Su, ${ }^{2}$ F. Jia, ${ }^{1}$ S. Han, ${ }^{1}$ W. J. Liu, ${ }^{1}$ D. L. Zhu, ${ }^{1}$ and X. C. Ma ${ }^{1}$ \\ ${ }^{1}$ Shenzhen Key Laboratory of Special Functional Materials, College of Materials Science and Engineering, Shenzhen University, \\ Shenzhen 518060, China \\ ${ }^{2}$ Institute of Optoelectronic Materials and Technology, South China Normal University, Guangzhou 510631, China
}

Correspondence should be addressed to Y. M. Lu; ymlu@szu.edu.cn

Received 7 June 2012; Accepted 21 August 2012

Academic Editor: Vincenza Crupi

Copyright (c) 2013 Y. M. Lu et al. This is an open access article distributed under the Creative Commons Attribution License, which permits unrestricted use, distribution, and reproduction in any medium, provided the original work is properly cited.

Photoluminescence (PL) of $\mathrm{ZnO}$ thin films prepared on $\mathrm{c}-\mathrm{Al}_{2} \mathrm{O}_{3}$ substrates by pulsed laser deposition (PLD) are investigated. For all samples, roomtemperature (RT) spectra show a strong band-edge ultraviolet (UV) emission with a pronounced low-energy band tail. The origin of this UV emission is analyzed by the temperature dependence of PL spectra. The result shows that the UV emission at RT contains different recombination processes. At low temperature donor-bound exciton $\left(\mathrm{D}^{0} \mathrm{X}\right)$ emission plays a major role in PL spectra, while the free exciton transition (FX) gradually dominates the spectrum with increasing temperatures. It notes that at low temperature an emission band (FA) appears in low energy side of $\mathrm{D}^{0} \mathrm{X}$ and FX and can survive up to RT. Further confirmation shows that the origin of the band FA can be attributed to the transitions of conduction band electrons to acceptors (e, $\left.A^{0}\right)$, in which the acceptor binding energy is estimated to be approximately $121 \mathrm{meV}$. It is concluded that at room temperature UV emission originates from the corporate contributions of the free exciton and free electrons-to-acceptor transitions.

\section{Introduction}

$\mathrm{ZnO}$, with a direct band gap of $3.37 \mathrm{eV}$ and a binding energy of exciton as high as $60 \mathrm{meV}$ at room temperature (RT), has been extensively studied as a candidate material for ultraviolet (UV) light emitting diodes (LEDs) and laser diodes (LDs) [1-3]. To realize the application of these devices, it is necessary to fabricate undoped $\mathrm{ZnO}$ thin films which avail to obtain a stable high-yield exciton emission at RT. However, it is well known that the fabrication of the high quality $\mathrm{ZnO}$ films is rather difficult. Because it is common to use $\mathrm{Al}_{2} \mathrm{O}_{3}$ as the substrate for the growth of $\mathrm{ZnO}$ thin films, $18 \%$ lattice mismatch between $\mathrm{ZnO}$ and $\mathrm{Al}_{2} \mathrm{O}_{3}$ results in the presence of various native defects in $\mathrm{ZnO}$ thin films [47]. These defects often control directly or indirectly doping, compensation, minority carrier lifetime, and luminescence efficiency. Consequently, it is very important to understand behavior of these defects in $\mathrm{ZnO}$-based materials. Photoluminescence (PL) emission spectroscopy is a useful method to examine the quality of the grown $\mathrm{ZnO}$ thin films, which may provide important information on understanding the carrier recombination processes and the role of defects in $\mathrm{ZnO}$.
In the reported PL spectra, the origin of the room temperature UV emission was extensively studied. Most of the authors suggested that the UV emission at RT originates from free exciton recombination [8-12]. However, Ohashi et al. reported that the most intense emission at RT for undoped crystals was not free-exciton recombination but was related to an unspecified localized state [13]. Zhao and Willander found that the room temperature UV emission contains two different transitions, in which one is related to the $\mathrm{ZnO}$ freeexciton and the other is related to the free-to-bound transition [14]. Up to now, the room temperature UV emission is still in debate. In addition, the controversies on PL properties also present to some UV emission bands obtained at low temperature. For example, the $3.31 \mathrm{eV}$ emission band observed in a great variety of $\mathrm{ZnO}$ materials has been interpreted controversially. Many authors have assigned this UV emission band to longitudinal-optical (LO) phonon replicas of the excitons (FX-LO) $[15,16]$, acceptor-bound excitons $\left(\mathrm{A}^{0} \mathrm{X}\right)$ [17], electron-hole recombination from donor acceptor pairs (DAP) [18], free electron-to-acceptor transition $\left(\mathrm{e}, \mathrm{A}^{0}\right)$ [19], and so forth. Noticeably, the $3.31 \mathrm{eV}$ emission band is also frequently observed in intentionally $\mathrm{p}$-doped $\mathrm{ZnO}$ [20-25]. 
Most of the works revealed that it is as a test criterion of p-type conductivity formed by substitutional acceptors. Recently, a remarkable work was reported in undoped $\mathrm{ZnO}$ epitaxial layers grown on a- $\mathrm{Al}_{2} \mathrm{O}_{3}$ substrates, in which the $3.31 \mathrm{eV}$ emission band observed at low temperature originates from a $\left(e, A^{0}\right)$ transition. And they give clear evidence that the localized acceptor states causing the $3.31 \mathrm{eV}$ luminescence should be associated with the stacking faults rather than the substitutional impurities [19].

On the other hand, the measurements of the electrical properties in undoped $\mathrm{ZnO}$ thin films grown on $\mathrm{Al}_{2} \mathrm{O}_{3}$ substrate show n-type conductivities with low electron mobilities of $<100 \mathrm{~cm}^{2} \mathrm{~V}^{-1} \mathrm{~s}^{-1}$, which is quite smaller than $300 \mathrm{~cm}^{2} \mathrm{~V}^{-1} \mathrm{~s}^{-1}$ based on the reported value in $\mathrm{ZnO}$ films grown on lattice-matched $\mathrm{ScAlMgO}_{4}$ substrates [2]. Such low electron mobility implies the existence of the scattering mechanisms due to unknown localized states. In conclusion, until now the impact of these defects on the optical and electrical properties of $\mathrm{ZnO}$ is still a subject of much debate. The clarifying of the PL origin not only can deepen and enrich the research of the impurity and defect behaviors but also is more advantageous for the development of $\mathrm{ZnO}$-based devices.

In this paper, we report near band edge UV luminescence in the $\mathrm{ZnO}$ thin films grown on $\mathrm{c}-\mathrm{Al}_{2} \mathrm{O}_{3}$ substrates by PLD method. The mechanism of the UV emission band is investigated by the temperature dependence of PL spectra. The $3.31 \mathrm{eV}$ emission band observed at low temperature is assigned to the transitions of conduction band electrons to acceptors. It is suggested that at room temperature UV emission is composed of two recombination processes. One is the free-exciton emission (FX), another is the free electron -to-acceptor emission (e, $\left.\mathrm{A}^{0}\right)$.

\section{Experiment}

$\mathrm{ZnO}$ thin films were fabricated on $\mathrm{c}-\mathrm{Al}_{2} \mathrm{O}_{3}$ substrates by using a KrF excimer laser (Lamda Physics Compexpro 205, $\lambda=248 \mathrm{~nm}, \tau=20 \mathrm{~ns}$ pulse duration). The laser beam was focused onto a rotating target at a $45^{\circ}$ angle of incidence, and the energy density of the laser beam at the target surface was maintained at about $2 \mathrm{~J} / \mathrm{cm}^{2}$. A $99.99 \%$ purity $\mathrm{ZnO}$ ceramic target with the thickness of $4 \mathrm{~mm}$ and the diameter of $60 \mathrm{~mm}$ was used as source materials.

$\mathrm{Al}_{2} \mathrm{O}_{3}$ substrates degreased in acetone and methanol for $10 \mathrm{~min}$, respectively, and then etched in a hot $\left(160^{\circ} \mathrm{C}\right)$ solution of $\mathrm{H}_{2} \mathrm{SO}_{4}: \mathrm{H}_{3} \mathrm{PO}_{4}=3: 1$ for $15 \mathrm{~min}$., followed by a rinse in deionized water and dried by the high-pure nitrogen gas before being loaded into the growth chamber. Prior to growth, the chemical cleaned substrates were thermally treated at $800^{\circ} \mathrm{C}$ in high vacuum atmosphere $\left(\sim 6 \times 10^{-4} \mathrm{~Pa}\right)$ for about $30 \mathrm{~min}$ to remove the surface contaminants. Sequentially, $\mathrm{ZnO}$ was deposited on this treated substrate at $700^{\circ} \mathrm{C}$ for $120 \mathrm{~min}$. In the growth process, $\mathrm{O}_{2}$ partial pressure in the growth chamber was varied from 0.2 to $5 \mathrm{~Pa}$. The repetition frequency of the laser was $5 \mathrm{~Hz}$, and the targetsubstrate distance was $8.5 \mathrm{~cm}$.
After growth, the sample quality was confirmed by a Rigaku O/max-RA X-ray diffractometer with $\mathrm{Cu} K_{\alpha}$ radiation $(\lambda=0.1542 \mathrm{~nm})$. Photoluminescence spectra were measured at different temperatures. The sample was attached to the cold finger of an optical cryostat in conjunction with a cryogenic refrigerator and cooled down to $\sim 10 \mathrm{~K}$. The $325 \mathrm{~nm}$ line of a He-Cd laser with a power of $20 \mathrm{~mW}$ was used as the excitation source. The photoluminescence from the sample was dispersed through a monochromator (ZLX-FS Omni $\lambda$ 3005) and detected by a photomultiplier tube (Hamamatsu R928) followed by a photon counter (Zolix DCS200PC). The carrier concentration and Hall mobility were measured by ET-9007 Hall measurement system through the Van de Pauw method.

\section{Results and Discussion}

Figure 1 shows the patterns of X-ray diffraction (XRD) for four samples of $\mathrm{ZnO}$ thin films grown on $\mathrm{c}-\mathrm{Al}_{2} \mathrm{O}_{3}$ substrates at different $\mathrm{O}_{2}$ partial pressures in the growth chamber, which are $5,3,1,0.5 \mathrm{~Pa}$ for the samples $\mathrm{A}, \mathrm{B}, \mathrm{C}$, and $\mathrm{D}$, respectively. It is noted that besides the $\mathrm{Al}_{2} \mathrm{O}_{3}$ (006) peak, only $\mathrm{ZnO}$ (002) and (004) diffraction peaks can be observed for all samples. This indicates that the grown $\mathrm{ZnO}$ thin films have the wurtzite structure with a high $c$-axis orientation. To further confirm the crystal quality of the $\mathrm{ZnO}$ films, XRD (103) $\phi$-scan measurements were performed. The inset of Figure 1 shows the measured result for the sample A. It is clearly seen the six peaks separated by $60^{\circ}$ with almost same intensities, indicating the formation of a sixfold symmetric single-crystal $\mathrm{ZnO}$.

Figure 2 shows photoluminescence (PL) spectra in UV region range for the above samples at $\mathrm{RT}$ excited by a $\mathrm{He}-\mathrm{Cd}$ laser with $325 \mathrm{~nm}$ line. As seen in Figure 2, one UV emission band with a central wavelength of $377.5 \mathrm{~nm}(3.284 \mathrm{eV})$ can be observed for the four samples. It is obvious that this UV emission band has a large linewidth $(>100 \mathrm{meV})$ and one shoulder (arrow in the figure) can be clearly seen at lower-energy side of this peak. The ZnO RT UV emission is extensive reported as a characteristic excitonic emission in the literatures [8-12]. In addition, Most of the works indicated that low-energy band tail of UV peak at RT is associated to LO-phonon replica of free exciton $[16,21]$.

In order to study the origin of the room temperature UV emission band, the temperature dependence of the PL spectrum from the $\mathrm{ZnO}$ thin films grown on a sapphire substrate has been measured. Figure 3 shows the PL spectra at various temperatures for the sample A. At $10 \mathrm{~K}$, the spectrum mainly composed of a strong emission of $\mathrm{D}^{0} \mathrm{X}$ band and a weak band labeled FA located at 3.355 and $3.309 \mathrm{eV}$, respectively. As temperature increases to $50 \mathrm{~K}$, the FA-LO band appears in low energy side of the band FA. In addition, one peak (FX) can be clearly observed in high energy side of $\mathrm{D}^{0} \mathrm{X}$ band at $50 \mathrm{~K}$ and becomes stronger and stronger with temperature increasing to $130 \mathrm{~K}$. At $90 \mathrm{~K}$, the $\mathrm{FX}$ at $3.370 \mathrm{eV}$ is comparable in intensity to the remaining $\mathrm{D}^{0} \mathrm{X}$ emission at $3.350 \mathrm{eV}$. As the temperature increases from 130 to $260 \mathrm{~K}$, the intensity of $\mathrm{D}^{0} \mathrm{X}$ band decreases rapidly and the FX emission 


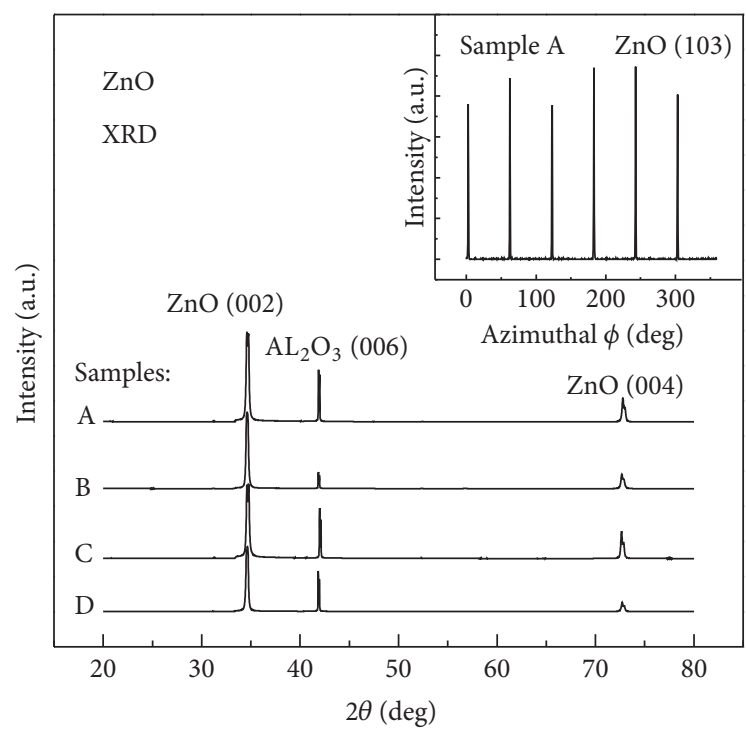

Figure 1: XRD spectra of $\mathrm{ZnO}$ thin films grown on c- $\mathrm{Al}_{2} \mathrm{O}_{3}$ substrate. The inset is $\phi$-scan curve of the (103) reflection of sample A.

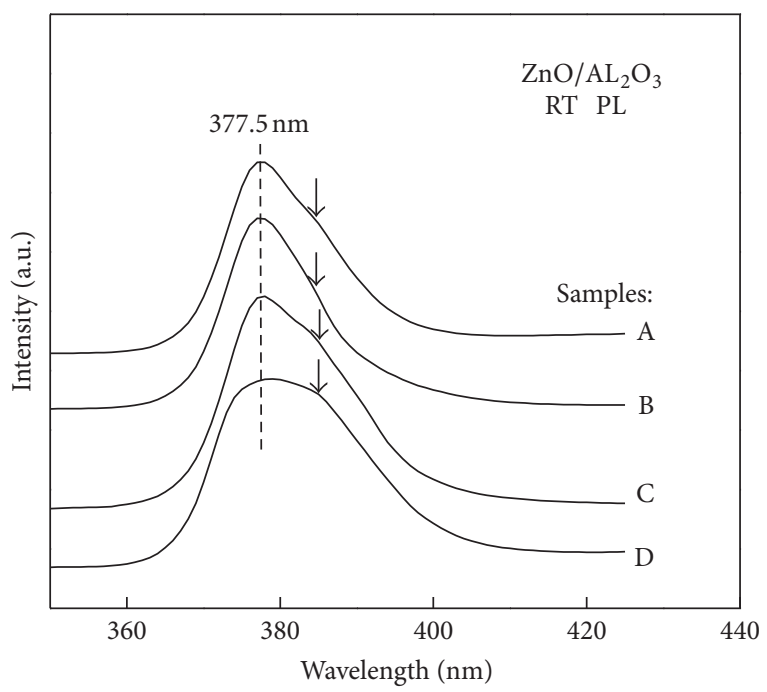

FIgURE 2: UV PL spectra of the grown $\mathrm{ZnO}$ thin films at room temperatures.

band becomes increasingly important in spite of its intensity decreases with increasing of temperature. It notes that at $110 \mathrm{~K}$ an emission band labeled FA-2LO appears in low energy side of the FA-LO band, and the bands of FA, FA-LO, and FA-2LO can survive up to $260 \mathrm{~K}$. Significantly, a careful study of these bands should be necessary to consider because of their contribution to the room temperature UV emission.

Figure 4 shows the fitted spectra by multipeaks of Lorentzian line shape at the four typical temperatures. According to their energy values, the $\mathrm{FX}$ and $\mathrm{D}^{0} \mathrm{X}$ peaks were attributed to the emission of free exciton and the recombination of excitons bound to neutral donors, respectively. As reported in [18], $\mathrm{D}^{0} \mathrm{X}$ assigned to donor-bound excitons with $10-15 \mathrm{meV}$ binding energy dominates in low temperature

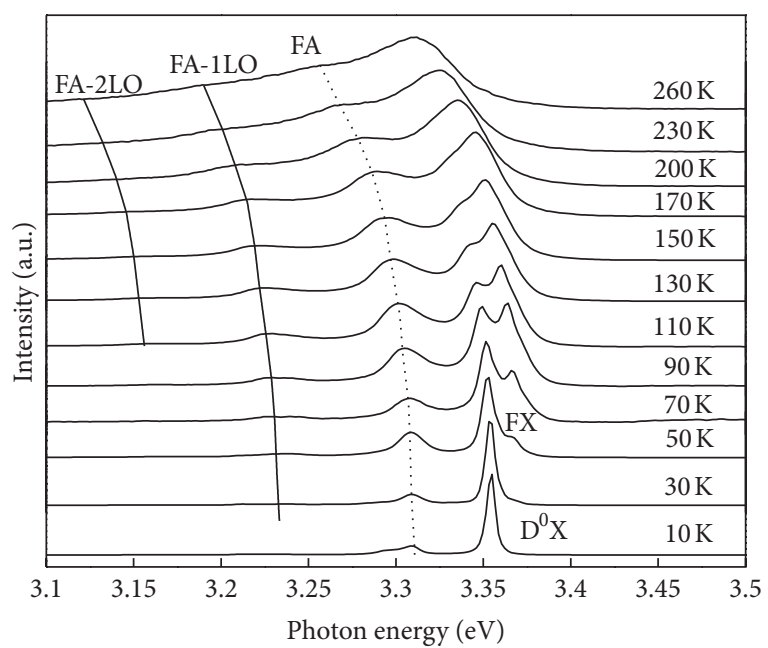

Figure 3: Temperature-dependent PL spectra of sample A. The spectra were normalized and shifted vertically for clarity.

spectra and the free-exciton recombination plays a major role in high temperature. By comparing with the peak positions of the FA and FX, two peaks have the energy spacing of about $47 \mathrm{meV}$, which is less than the energy of $\mathrm{ZnO} \mathrm{LO}$ phonon [17]. Therefore, it can be believed that the FA peak should be associated with the impurity or defects rather than the first LO phonon replica of the free exciton recombination (FX). In our previous work, PL spectrum at $80 \mathrm{~K}$ of undoped $\mathrm{ZnO}$ thin film grown by plasma-assisted molecular beam epitaxy (P-MBE) clearly shows the first and the second LO phonon replica of FX (FX-LO and FX-2LO) [21]. In this paper, the fabrication of the samples was used by PLD method on a deviation from the stoichiometric ratio condition. The measure of the film thicknesses shows the increase of the growth rate with increasing $\mathrm{O}_{2}$ partial pressure. This indicates that the growth of the films is on a rich- $\mathrm{Zn}$ condition, resulting in the observation of FA emission related to the defects. For FA-LO and FA-2LO bands, we note that the energy differences between the FA-LO and FA-2LO bands to the FA band are close to one and two LO phonon energies of $\mathrm{ZnO}$. This implies that FA-LO and FA-2LO bands should correspond to the first and the second LO phonon replica of the FA band.

Figure 5(a) exhibits the temperature $(T)$ dependence of integral PL intensities (I) for FX band. One can clearly see that at high temperature, the emission intensity represents the decrease with temperature increasing due to the thermal quenching. The dependence of $I$ on $T$ for FX band can be fitted by the following formula

$$
I=\frac{I_{0}}{1+A \exp \left(-E_{a} /\left(k_{B} T\right)\right)},
$$

where $I_{0}$ is the peak intensity at temperature $T=0 \mathrm{~K}, A$ is a parameter, $E_{a}$ is the activation energy in the thermal quenching process, and $k_{B}$ is the Boltzmann constant. From the plots (solid line), the thermal activation energy is estimated to be $59 \mathrm{meV}$ for FX band. This value agrees well with the free exciton binding energy of $\mathrm{ZnO}(\sim 60 \mathrm{meV})$ [1-4]. 

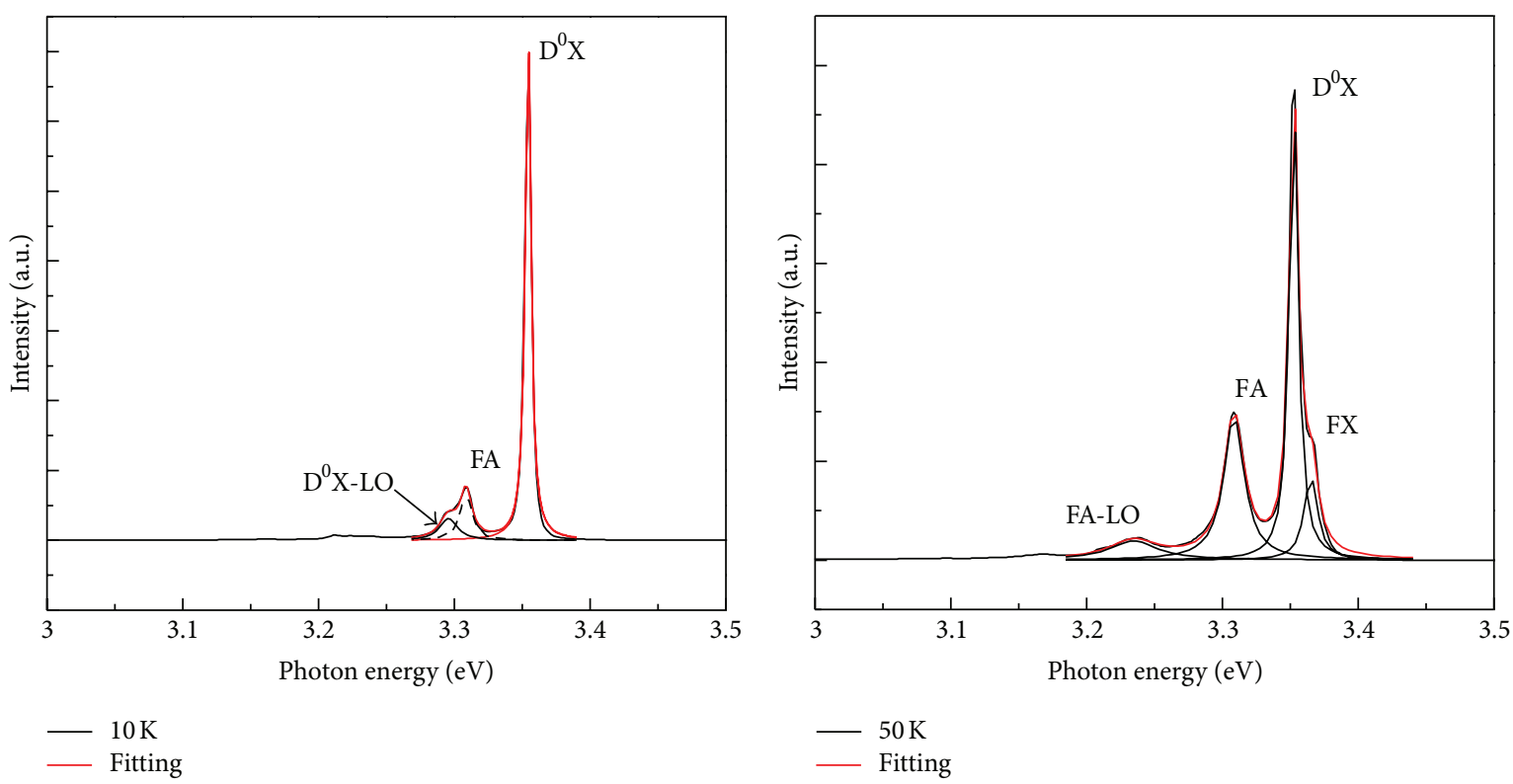

(a)

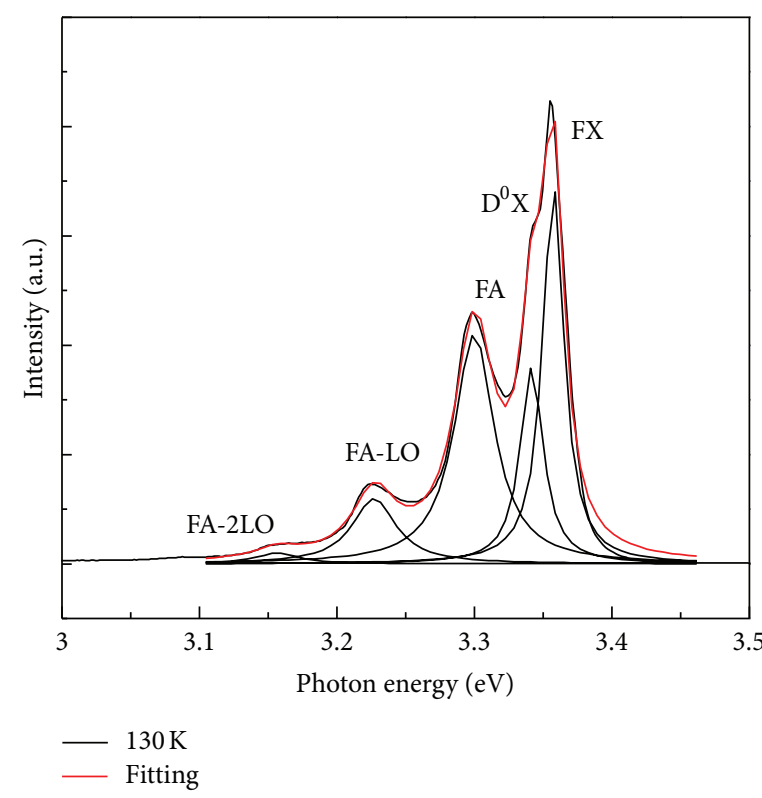

(c) (b)

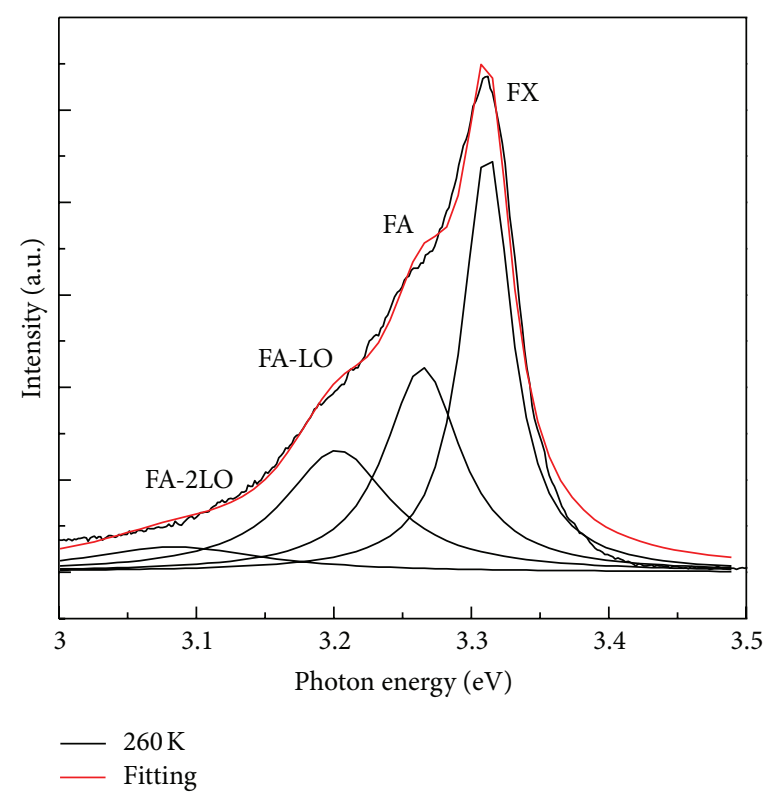

(d)

Figure 4: The fits of PL spectra by Lorentzian line shape at $10 \mathrm{~K}$ (a), $50 \mathrm{~K}(\mathrm{~b}), 130 \mathrm{~K}(\mathrm{c})$ and $260 \mathrm{~K}$ (d).

Figure 5(b) shows the intensity ratio $R_{0}$ of FA to FA$\mathrm{LO}$ (FA/FA-LO) as a function of temperature. It can be seen that the $R_{0}$ value presents a downtrend as the temperature increases. In the same temperature range, the phonon replicas could be much stronger than the no-phonon recombination due to self-absorption, but the intensity ratio of the first to the second LO-phonon replica should increase linearly with temperature [26, 27]. As shown in Figure 5(b), it is found that $R_{0}$ is decreased with the temperature from 90 to $260 \mathrm{~K}$. Thus, FA-LO band is not the second LO replica of FX, but rather is the first LO replica of FA, that is, FA band cannot be the first LO replica of FX.
Although we excluded that the FA band is from the first LO replica of the free exciton, the luminescence band still exist many other controversial luminescent mechanisms [14, $15,17,18,28]$. The comparison with literature $[14,19,28]$ strongly suggests that the observed FA band originates from free-to-acceptor transition, that is, the recombination of an electron from the conduction band with a hole bound to an acceptor state, labeled $\left(e, A^{0}\right)$. A further confirmation of this assignment will be demonstrated below. In Figure 3, PL spectra exhibit that the FA band at low energy side of $\mathrm{D}^{0} \mathrm{X}$ and $\mathrm{FX}$ can be clearly observed in whole temperature range from 11 to $260 \mathrm{~K}$. At lower temperature $(<130 \mathrm{~K})$, 


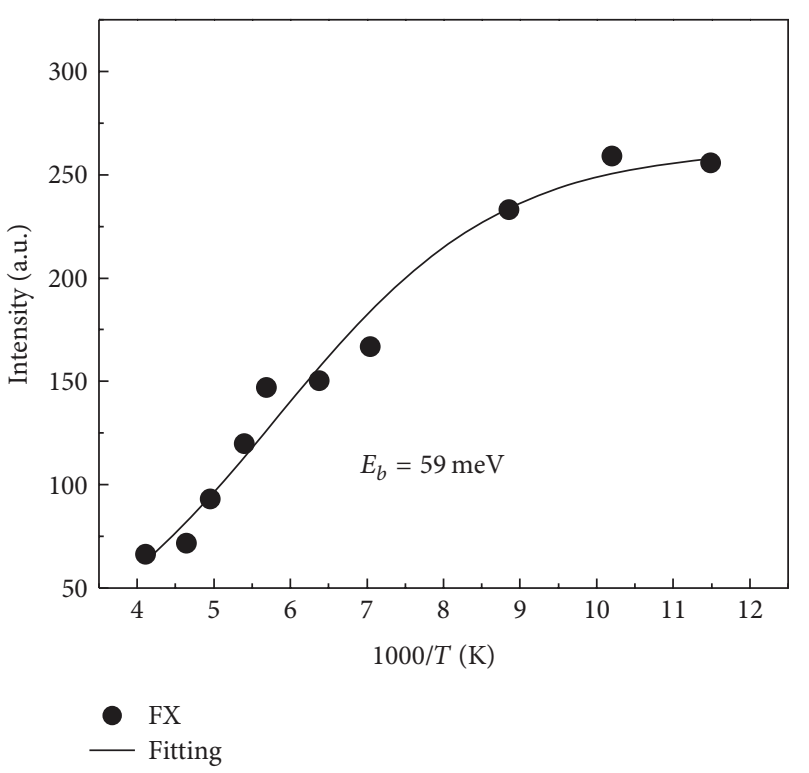

(a)

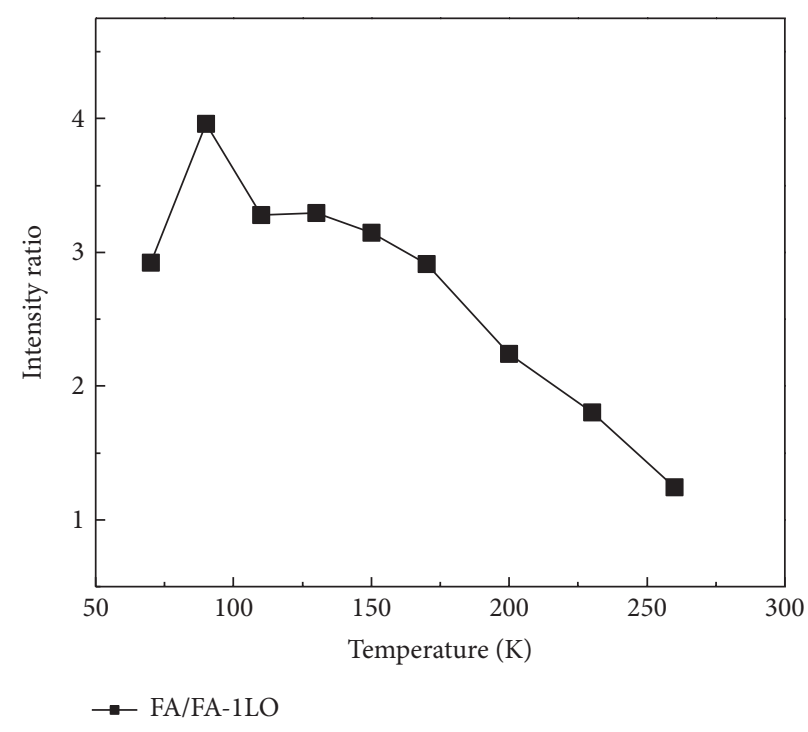

(b)

Figure 5: (a) The integrated intensity of the FX emission as a function of the temperature for sample A. The solid lines are the curves fitted by formula (1). (b) The intensity ratio $I_{0}$ of FA emission to FA-LO emission at various temperatures for sample A.

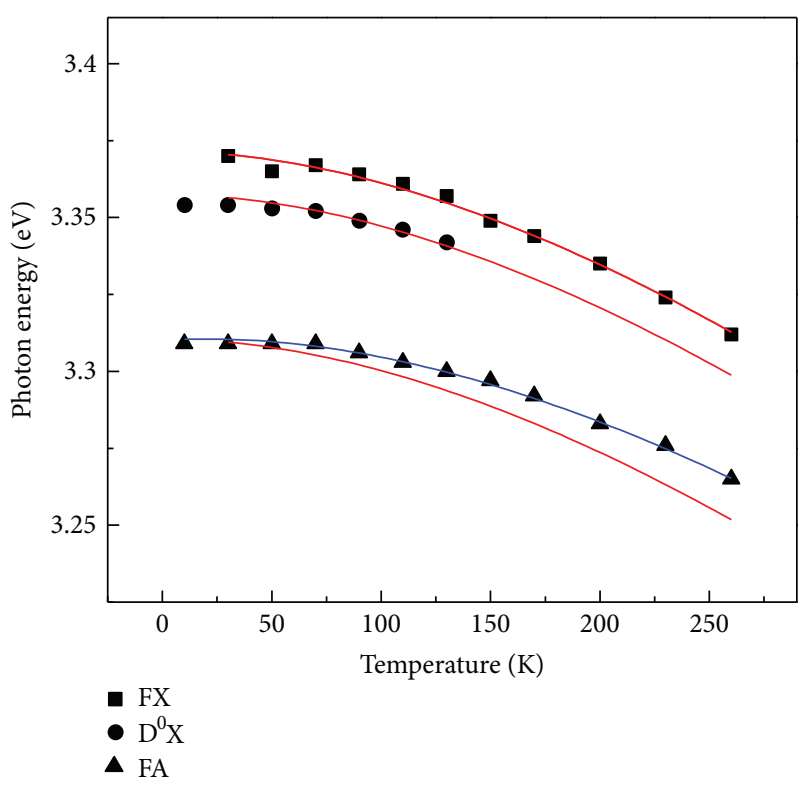

FIGURE 6: Temperature dependences on the peak energies of $\mathrm{FX}(\mathbf{\bullet})$, $D^{0} X(\bullet)$ and $\mathrm{FA}(\boldsymbol{\Delta})$ emissions for $\mathrm{ZnO}$ thin films grown on $\mathrm{c}-\mathrm{Al}_{2} \mathrm{O}_{3}$ substrate. The solid lines are the curves fitted by formula (2).

the intensity of the FA, and FA-LO bands gradually becomes strong with increase temperature. At $130 \mathrm{~K}$, four evident emission peaks labeled FX, $\mathrm{D}^{0} \mathrm{X}, \mathrm{FA}$, and FA-LO are located at $3.360 \mathrm{eV}, 3.346 \mathrm{eV}, 3.301 \mathrm{eV}$, and $3.227 \mathrm{eV}$, respectively. With further increases in $\mathrm{ZnO}$ sample temperature, the FA band deceases in relative intensity and becomes more pronounced at the high-energy tail. This is a typical feature of the freeto-bound transition [19]. In undoped $\mathrm{ZnO}$, typical donors have binding energies in the range of 46-63 meV [29], while acceptor binding energy is larger $(>100 \mathrm{meV})$ [30]. Due to the release of the electrons from donors with smaller binding energy, the electron concentration in the conduction band increases with increasing temperature $(<130 \mathrm{~K})$, resulting in the FA emission intensity increases. For $>130 \mathrm{~K}$, the observed thermal quenching of the FA band is related to hole release from acceptors.

In order to verify that the recombination of free-toacceptor is responsible for the observed FA band, the temperature dependent peak position is analyzed, as shown in Figure 6. The open circles in Figure 6 are the data generated from the FA band. Because the temperature dependence of the free-to-bound transition energy differs from the bandgap energy by $k_{B} T / 2$, a curve-fitting analysis of the temperature dependence of the FA transition energy by using the following formula [31]:

$$
\begin{gathered}
E_{\mathrm{FA}}(T)=E_{g}(T)-E_{a}+\frac{1}{2} k_{B} T, \\
E_{g}(T)=E_{g}(0)-\frac{\alpha T^{2}}{(T+\beta)},
\end{gathered}
$$

where $E_{g}(T)$ and $E_{\mathrm{FA}}(T)$ are the temperature-dependent band gap energy and FA band energy, respectively, $E_{a}$ is the acceptor binding energy, $k_{B}$ is the Boltzmann constant, $\alpha$ and $\beta$ are constants, $E_{g}(0)$ is the band gap energy at $T=0 \mathrm{~K}$. The blue curves in Figure 6 represent the results of the best fit according to (2). The energy $E_{a}$ is obtained to be $121 \mathrm{meV}$. The fitted values of $E_{g}(0), \alpha$ and $\beta$ are equal to $3.440 \mathrm{eV}$, $8.6 \times 10^{-4} \mathrm{eV} / \mathrm{K}$ and $800 \mathrm{~K}$, respectively, which are in good agreement with those reported by Wang and Giles [31]. This fact provides evidence that the observed FA transition has 
the characteristic of the free-to-bound transition. In Figure 6 , the $\mathrm{FX}$ and $\mathrm{D}^{0} \mathrm{X}$ peak energies from PL spectra are also plotted with solid square and solid circle symbols. As can be seen, although the FX, the $\mathrm{D}^{0} \mathrm{X}$, and the FA transition energies are reduced with increasing temperature, the change of their transition energies is different. The transition energies of the free and bound excitons show similar temperature dependence as the band-gap energy (red lines). Hence, the redshift of the FA emission peak is significantly smaller than the $\mathrm{FX}$ and $\mathrm{D}^{0} \mathrm{X}$. This further identifies the FA band as a freeto-bound transition.

Though we identify the FA band as a free-to-bound transition, a further investigation is required to clarify this bound state is donor-like or acceptor-like. Because this band around $3.310 \mathrm{eV}$ always appears in p-type $\mathrm{ZnO}$, not only in $\mathrm{N}$-doped [20, 21] but also in P-doped [22, 23], and Asdoped $[24,25]$ samples, it has been assigned to $\left(e, A^{0}\right)$ transition related to these substitutional acceptors. However, this luminescence band has indeed frequently been observed in undoped $\mathrm{ZnO}$ samples, especially in $\mathrm{ZnO}$ nanostructure materials $[14,15,17,18]$. In our previous works, the $3.31 \mathrm{eV}$ luminescence assigned (e, $\mathrm{A}^{0}$ ) transition is observed in $\mathrm{N}$ doped p-type $\mathrm{ZnO}$ thin films [21] and $\mathrm{ZnO}$ nanowalls [28]. If these reported results in undoped $\mathrm{ZnO}$ are consistent with p-type $\mathrm{ZnO}$, that is, the observed luminescence band around $3.31 \mathrm{eV}$ is ralated to acceptors, it is necessary to discuss the origin of the acceptors in undoped n-type $\mathrm{ZnO}$.

Recently, some research results confirm the existence of certain acceptor states in $\mathrm{n}$-type $\mathrm{ZnO}$ with relatively high concentrations $[19,32]$. Janotti and Van De Walle given the acceptor/donor concentration ratio of 0.41 in $\mathrm{ZnO}: \mathrm{Ga}$ samples and suggested the dominant acceptors are likely zinc vacancies $\left(V_{\mathrm{Zn}}\right)$ and/or neutral complexes related to $V_{\mathrm{Zn}}$. Indeed, the theoretical study shows that $V_{\mathrm{Zn}}$ is deep acceptor with a low formation energy, and it can act as compensating centers in n-type $\mathrm{ZnO}$ [5]. Simultaneously on the experimental, $V_{\mathrm{Zn}}$ has been directly identified as the dominant acceptor in as-grown $\mathrm{ZnO}$ [7]. On the other hand, Schirra and Schneider reported that the acceptor states related to stacking fault in $\mathrm{ZnO}$ films grown on a- $\mathrm{Al}_{2} \mathrm{O}_{3}$ substrates [19], in which the $3.31-\mathrm{eV}$ luminescence assigned to $\left(\mathrm{e}, \mathrm{A}^{0}\right)$ transition is found to be related to a high local density of acceptors in conjunction with crystallographic defects. The existence of these acceptors with the estimated concentration of $10^{18} \sim$ $10^{20} \mathrm{~cm}^{-3}$, which might exceed the donor concentration, will play a vital role for the electrical properties [19, 32]. From this consideration, the room temperature electrical properties of $\mathrm{ZnO}$ films were measured by the four-probe van der Pauw method. Based on these measurements, the grown samples show n-type characteristics with a resistivity of the order of $10 \Omega \cdot \mathrm{cm}$. In addition, obtaining such high resistivity corresponds to a mobility of $10 \mathrm{~cm}^{2}(\mathrm{~V} \mathrm{~s})^{-1}$ and a carrier concentration of $10^{15} \mathrm{~cm}^{-3}$. It is well known that undoped $\mathrm{ZnO}$ films has a nature of the residual n-type conductivity due to donor-like intrinsic defects, such as oxygen vacancies $\left(V_{O}\right)$ and interstitial zinc atoms $\left(\mathrm{Zn}_{i}\right)$. In the majority of the pertinent works $[2,3]$, the obtained carrier concentration in undoped $\mathrm{ZnO}$ films is the order of $10^{16}-10^{18} \mathrm{~cm}^{-3}$. Obviously, these values are much higher than that of our sample. Thus, high resistivity in our work is suggested to be due to the compensating effect formed by large numbers of acceptor states. Here, the acceptors likely arising from the native defects will cause the electrical properties degradation. Not only such, these acceptor states will bring important influence on room temperature UV emission. To identify the acceptor origin need further investigation in detail.

\section{Conclusion}

In summary, we have performed a detailed study about photoluminescence properties of $\mathrm{ZnO}$ thin films grown on c$\mathrm{Al}_{2} \mathrm{O}_{3}$ substrates by pulsed laser deposition. The origin of $\mathrm{UV}$ emissions at RT is studied carefully by measuring different temperature spectra of $\mathrm{ZnO}$ thin films. The result shows at low temperature donor-bound exciton emission plays a major role in PL spectra, while the free-exciton transition gradually dominates the spectrum with increasing temperatures. The room temperature UV emission contains two different transitions. One is related to the $\mathrm{ZnO}$ free-exciton and the other is related to the free-to-bound transition. The focus is put on the confirmation of this the free-tobound transition observed at $3.309 \mathrm{eV}$ at low temperature. It is strongly suggested that the $3.309 \mathrm{eV}$ band originates from free-electrons-to-acceptor recombination. The acceptor binding energy is estimated to be about $121 \mathrm{meV}$.

\section{Acknowledgments}

This work was supported by the National Natural Science Foundation of China under Grant no. 60976036, the Science and Technology Research Items of Shenzhen and the Items of Shenzhen Key Laboratory of Special Functional Materials (Grant nos. T201101 and T201109).

\section{References}

[1] Z. K. Tang, G. K. L. Wong, P. Yu et al., "Room-temperature ultraviolet laser emission from self-assembled $\mathrm{ZnO}$ microcrystallite thin films," Applied Physics Letters, vol. 72, no. 25, pp. 3270-3272, 1998.

[2] A. Tsukazaki, A. Ohtomo, T. Onuma et al., "Repeated temperature modulation epitaxy for p-type doping and light-emitting diode based on ZnO," Nature Materials, vol. 4, no. 1, pp. 42-46, 2005.

[3] Y. R. Ryu, J. A. Lubguban, T. S. Lee et al., "Excitonic ultraviolet lasing in ZnO-based light emitting devices," Applied Physics Letters, vol. 90, no. 13, Article ID 131115, 2007.

[4] A. F. Kohan, G. Ceder, D. Morgan, and C. G. Van De Walle, "First-principles study of native point defects in $\mathrm{ZnO}$," Physical Review B, vol. 61, no. 22, pp. 15019-15027, 2000.

[5] A. Janotti and C. G. Van De Walle, "Native point defects in ZnO," Physical Review B, vol. 76, no. 16, Article ID 165202, 2007.

[6] N. Y. Garces, N. C. Giles, L. E. Halliburton et al., "Production of nitrogen acceptors in $\mathrm{ZnO}$ by thermal annealing," Applied Physics Letters, vol. 80, no. 8, pp. 1334-1336, 2002. 
[7] F. Tuomisto, V. Ranki, K. Saarinen, and D. C. Look, "Evidence of the $\mathrm{Zn}$ vacancy acting as the dominant acceptor in n-type $\mathrm{ZnO}$," Physical Review Letters, vol. 91, no. 20, Article ID 205502, 2003.

[8] D. M. Bagnall, Y. F. Chen, M. Y. Shen, Z. Zhu, T. Goto, and T. Yao, "Room temperature excitonic stimulated emission from zinc oxide epilayers grown by plasma-assisted MBE," Journal of Crystal Growth, vol. 184-185, pp. 605-609, 1998.

[9] Y. Chen, S. K. Hong, H. J. Ko, M. Nakajima, T. Yao, and Y. Segawa, "Plasma-assisted molecular-beam epitaxy of $\mathrm{ZnO}$ epilayers on atomically flat $\mathrm{MgAl}_{2} \mathrm{O}_{4}(111)$ substrates," Applied Physics Letters, vol. 76, no. 2, pp. 245-247, 2000.

[10] D. A. Lucca, D. W. Hamby, M. J. Klopfstein, and G. Cantwell, "Chemomechanical polishing effects on the room temperature photoluminescence of bulk $\mathrm{ZnO}$ : exciton-LO phonon interaction," Physica Status Solidi B, vol. 229, pp. 845-848, 2002.

[11] L. Wang and N. C. Giles, "Temperature dependence of the freeexciton transition energy in zinc oxide by photoluminescence excitation spectroscopy," Journal of Applied Physics, vol. 94, no. 2, pp. 973-978, 2003.

[12] Z. K. Tang, M. Kawasaki, A. Ohtomo, H. Koinuma, and Y. Segawa, "Self-assembled $\mathrm{ZnO}$ nano-crystals and exciton lasing at room temperature," Journal of Crystal Growth, vol. 287, no. 1, pp. 169-179, 2006.

[13] N. Ohashi, T. Ishigaki, N. Okada, T. Sekiguchi, I. Sakaguchi, and H. Haneda, "Effect of hydrogen doping on ultraviolet emission spectra of various types of $\mathrm{ZnO}$," Applied Physics Letters, vol. 80, no. 16 , pp. 2869-2871, 2002.

[14] Q. X. Zhao, M. Willander, R. E. Morjan, Q-H. Hu, and E. E. B. Campbell, "Optical recombination of $\mathrm{ZnO}$ nanowires grown on sapphire and Si substrates," Applied Physics Letters, vol. 83, no. 1, pp. 165-167, 2003.

[15] X. Wang, H. Iwaki, M. Murakami, X. Du, Y. Ishitani, and A. Yoshikawa, "Molecular beam epitaxy growth of single-domain and high-quality $\mathrm{ZnO}$ layers on nitrided (0001) sapphire surface," Japanese Journal of Applied Physics, vol. 42, no. 2, pp. L99-L101, 2003.

[16] J. Jie, G. Wang, Y. Chen et al., "Synthesis and optical properties of well-aligned $\mathrm{ZnO}$ nanorod array on an undoped $\mathrm{ZnO}$ film," Applied Physics Letters, vol. 86, no. 3, Article ID 031909, pp. 1-3, 2005.

[17] F. X. Xiu, Z. Yang, L. J. Mandalapu et al., "Donor and acceptor competitions in phosphorus-doped ZnO," Applied Physics Letters, vol. 88, pp. 152116-152118, 2007.

[18] B. P. Zhang, N. T. Binh, Y. Segawa, K. Wakatsuki, and N. Usami, "Optical properties of $\mathrm{ZnO}$ rods formed by metalorganic chemical vapor deposition," Applied Physics Letters, vol. 83, no. 8, pp. 1635-1637, 2003.

[19] M. Schirra, R. Schneider, A. Reiser et al., "Stacking fault related 3.31-eV luminescence at $130-\mathrm{meV}$ acceptors in zinc oxide," Physical Review B, vol. 77, no. 12, Article ID 125215, 2008.

[20] D. C. Look, D. C. Reynolds, C. W. Litton, R. L. Jones, D. B. Eason, and G. Cantwell, "Characterization of homoepitaxial ptype $\mathrm{ZnO}$ grown by molecular beam epitaxy," Applied Physics Letters, vol. 81, no. 10, pp. 1830-1832, 2002.

[21] J. W. Sun, Y. M. Lu, Y. C. Liu et al., "Nitrogen-related recombination mechanisms in $\mathrm{p}$-type $\mathrm{ZnO}$ films grown by plasmaassisted molecular beam epitaxy," Journal of Applied Physics, vol. 102, no. 4, Article ID 043522, 2007.

[22] J. D. Ye, S. L. Gu, F. Li et al., "Correlation between carrier recombination and p-type doping in $\mathrm{P}$ monodoped and In-P codoped ZnO epilayers," Applied Physics Letters, vol. 90, no. 15, Article ID 152108, 2007.
[23] T. Nobis, E. M. Kaidashev, A. Rahm, M. Lorenz, J. Lenzner, and M. Grundmann, "Spatially inhomogeneous impurity distribution in ZnO micropillars," Nano Letters, vol. 4, no. 5, pp. 797-800, 2004.

[24] Y. R. Ryu, S. Zhu, D. C. Look, J. M. Wrobel, H. M. Jeong, and H. W. White, "Synthesis of p-type ZnO films," Journal of Crystal Growth, vol. 216, no. 1, pp. 330-334, 2000.

[25] H. S. Kang, G. H. Kim, D. L. Kim, H. W. Chang, B. D. Ahn, and S. Y. Lee, "Investigation on the $\mathrm{p}$-type formation mechanism of arsenic doped p -type $\mathrm{ZnO}$ thin film," Applied Physics Letters, vol. 89, no. 18, Article ID 181103, 2006.

[26] C. Klingshirn, "Luminescence of $\mathrm{ZnO}$ under high one- and twoquantum excitation," Physica Status Solidi B, vol. 71, no. 2, pp. 547-556, 1975.

[27] B. Segall and G. D. Mahan, "Phonon-assisted recombination of free excitons in compound semiconductors," Physical Review, vol. 171, no. 3, pp. 935-948, 1968.

[28] S. C. Su, Y. M. Lu, Z. Z. Zhang et al., "Oxygen flux influence on the morphological, structural and optical properties of $\mathrm{Zn}_{1-x} \mathrm{Mg}_{x} \mathrm{O}$ thin films grown by plasma-assisted molecular beam epitaxy," Applied Surface Science, vol. 254, no. 15, pp. 4886-4890, 2008.

[29] B. K. Meyer, H. Alves, D. M. Hofmann et al., "Bound exciton and donor-acceptor pair recombinations in ZnO," Physica Status Solidi B, vol. 241, no. 2, pp. 231-260, 2004.

[30] D. C. Look, "Electrical and optical properties of p-type $\mathrm{ZnO,"}$ Semiconductor Science and Technology, vol. 20, no. 4, pp. S55-S61, 2005.

[31] L. Wang and N. C. Giles, "Determination of the ionization energy of nitrogen acceptors in zinc oxide using photoluminescence spectroscopy," Applied Physics Letters, vol. 84, no. 16, pp. 3049-3051, 2004.

[32] D. C. Look, K. D. Leedy, D. H. Tomich, and B. Bayraktaroglu, "Mobility analysis of highly conducting thin films: application to ZnO," Applied Physics Letters, vol. 96, no. 6, Article ID 062102 , 2010 . 

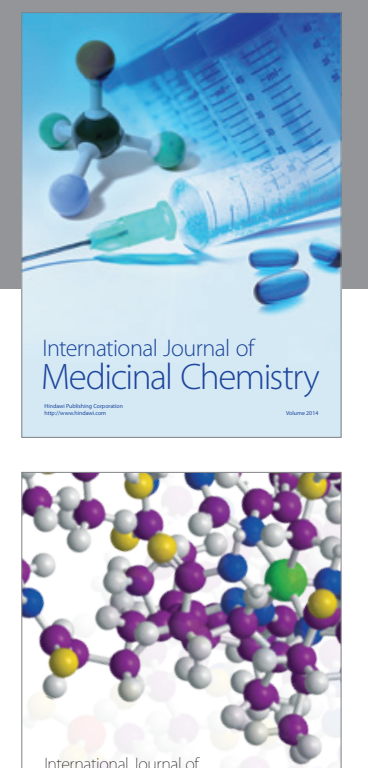

\section{Carbohydrate} Chemistry

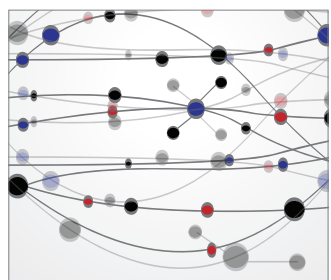

The Scientific World Journal
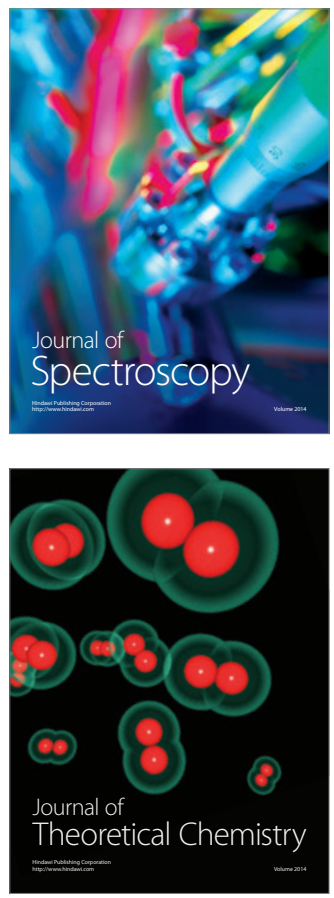
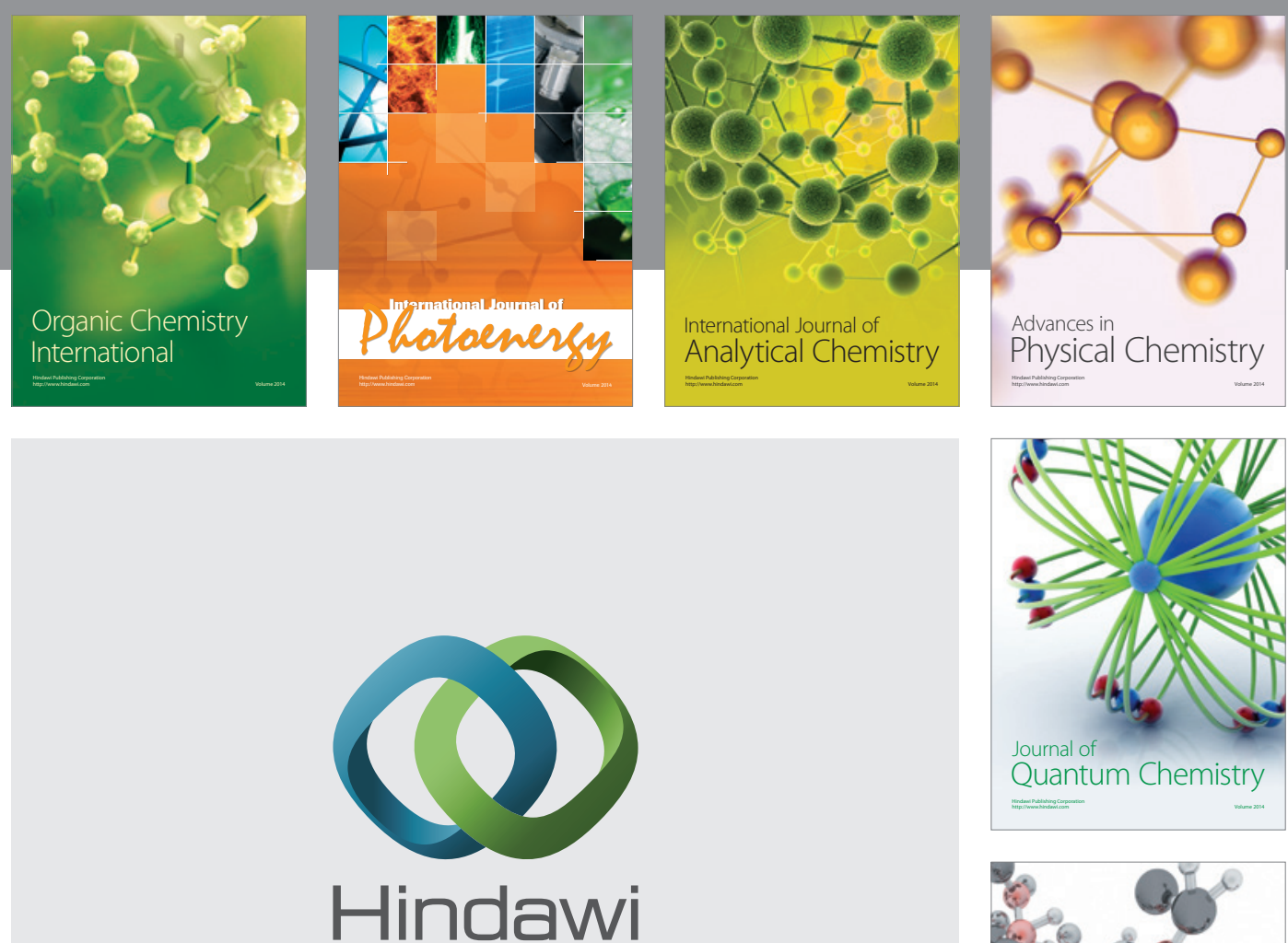

Submit your manuscripts at

http://www.hindawi.com

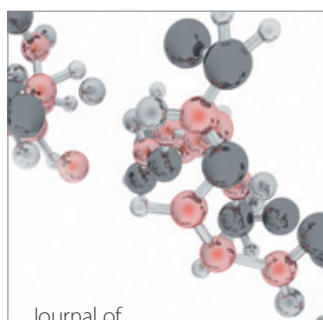

Analytical Methods

in Chemistry

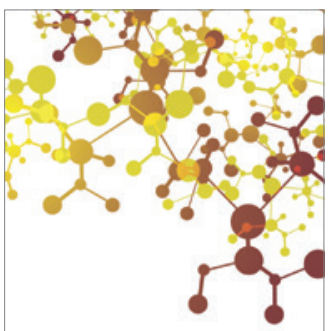

Journal of

Applied Chemistry

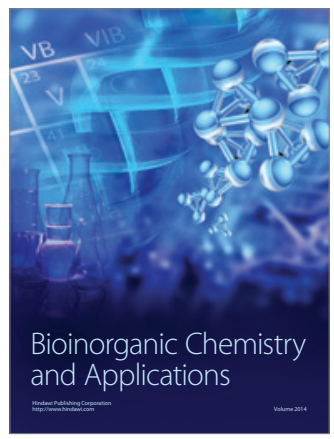

Inorganic Chemistry
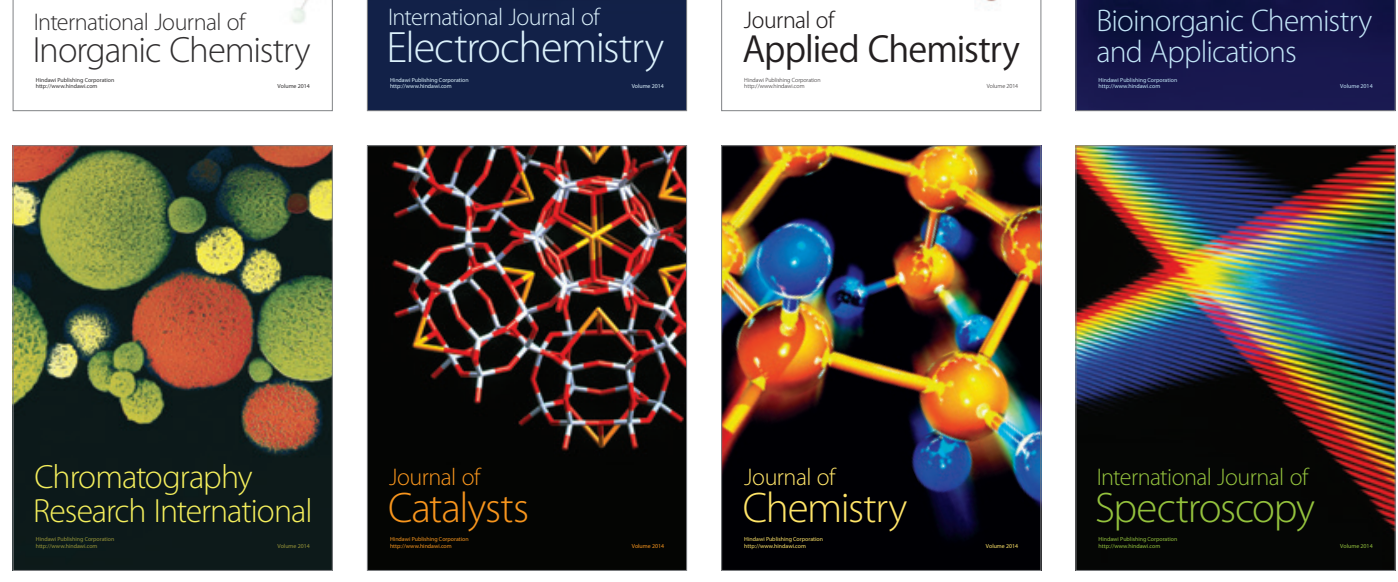